\title{
Investigation of the Effect of Berberine with Arginase Activity and Oxidant- Antioxidant Parameters on Bortezomib-Induced Spleen Injury in Rats
}

\author{
Mustafa İLERİTÜRK' ${ }^{*}$, Tuba DOĞAN1 ${ }^{1}$ Özge KANDEMİR² \\ ${ }^{1}$ Ataturk University, Faculty of Veterinary Medicine, Department of Biochemistry, 25240, Erzurum, Turkey \\ ${ }^{2}$ Veterinary Control Institute, 25070, Erzurum, Turkey
}

\begin{abstract}
The aim of the study was to investigate the effects of berberine, one of the natural flavonoids, against spleen damage caused by bortezomib (BTZ), which was widely used in the treatment of cancer. Male Sprague-Dawley rats were randomly divided into five groups: a control group, BTZ-treated group, berberine alone treated group $100 \mathrm{mg} / \mathrm{kg}$, BTZ + berberine $50 \mathrm{mg} / \mathrm{kg}$ treated group, and BTZ+berberine $100 \mathrm{mg} / \mathrm{kg}$ treated group. Analysis results showed that BTZ caused oxidative stress by reducing antioxidant enzyme activities such as glutathione peroxidase (GPx), superoxide dismutase (SOD) and catalase (CAT) and glutathione (GSH) levels, thereby increasing malondialdehyde (MDA) levels which is the end product of lipid peroxidation. However, by increasing the enzymatic and non-enzymatic antioxidant levels, berberine was found to reduce BTZ-induced oxidative stress and MDA levels significantly. It was also observed that BTZ decreased the total antioxidant capacity (TAC) and increased the total oxidant capacity (TOC) and nitric oxide (NO) levels, while the berberine made these parameters closer to the control group levels. Arginase activity was also measured in the study. When the results were examined, it was seen that BTZ suppressed arginase activity and BTZ and berberine combined administration regained arginase activity. Accordingly, it is thought that the berberine provides significant protection by lessening the oxidative and nitrosative stress triggered by BTZ in the spleen tissue, and after these results are supported by further studies, the berberine can be included among alternative treatment options.
\end{abstract}

Keywords: Berberine, Bortezomib, Oxidative Stress, Rat, Spleen

Ratlarda Bortezomib Kaynaklı Dalak Hasarı Üzerine Berberinin Etkisinin Arginaz Aktivitesi ve Oksidan-Antioksidan Parametreler ile İncelenmesi

ÖZ

Bu çalışmanın amacı; kanser tedavisinde yaygın olarak kullanılan bortezomib (BTZ) kaynaklı dalak hasarına karşı doğal bir flavonoid olan berberinin etkileri araştırmaktır. Bu amaçla çalışmada Sprague Dawley cinsi 35 adet erkek rat kontrol, BTZ, berberin $100 \mathrm{mg} / \mathrm{kg}$, BTZ+berberin $50 \mathrm{mg} / \mathrm{kg}$ ve BTZ+berberin $100 \mathrm{mg} / \mathrm{kg}$ olmak üzere rastlgele 5 gruba ayrıldı. Analiz sonuçları BTZ'nin glutatyon peroksidaz (GPx), süperoksit dismutaz (SOD) ve katalaz (KAT) gibi antioksidan enzim aktivitelerini ve glutatyon (GSH) düzeylerini azaltarak oksidatif strese neden olduğunu ve böylece lipid peroksidasyonunun son ürünü olan malondialdehit (MDA) seviyelerini artırdığını gösterdi. Bununla birlikte berberinin enzimatik ve non-enzimatik antioksidan düzeylerini artırması yoluyla BTZ kaynaklı oksidatif stresi hafiflettiği ve MDA seviyelerini önemli derecede azalttığı belirlendi. BTZ'nin ayrıca toplam antioksidan kapasite (TAK)'yi azalttığı, toplam oksidan kapasite (TOK) ve nitrik oksit (NO) seviyelerini ise arttığı görülürken berberinin bu parametreleri kontrol grubu seviyelerine yaklaştırdığı tespit edildi. Çalışmada ayrıca arginaz aktivitesi ölçüldü. Sonuçlar incelendiğinde BTZ'nin arginaz aktivitesini baskıladığı, BTZ ile birlikte berberin uygulamasının ise dalak dokusunda arginaz aktivitesini geri kazandırdığı görüldü. Birlikte ele alındığında berberinin dalak dokusunda BTZ'nin tetiklediği oksidatif ve nitrosatif stresi hafifleterek önemli derecede koruma sağladığı ve bu sonuçların daha ileri çalışmalar ile desteklendikten sonra berberinin alternatif tedavi seçenekleri arasına girebileceği düşünülmektedir.

Anahtar Kelimeler: Berberin, Bortezomib, Dalak, Oksidatif Stres, Rat

To cite this article: Illeritürk M. Doğan T. Kandemir Ö. Investigation of the Effect of Berberine with Arginase Activity and Oxidant-Antioxidant Parameters on Borteromib-Induced Spleen Injury in Rats. Kocatepe Vet J. (2021):14(1):6-15

Submission: $12.10 .2020 \quad$ Accepted: 18.12.2020 Published Online: 31.12 .2020

ORCID ID; MI: 0000-0002-4581-4492, TD: 0000-0003-4039-3437, ÖK: 0000-0001-8884-4186

*Corresponding author e-mail: m.ileriturk@atauni.edu.tr 


\section{GİRİ̧̧}

Sitostatik veya anti-neoplastik ilaçlar olarak da bilinen antikanser ilaçlar, kanser tedavisinde etkili olan güçlü mekanizmalara sahiptir (Kucukler ve ark. 2020a). Bu ilaçların büyük bir kısmı, DNA fonksiyonunu ve hücre sinyalini bozarak kanser hücrelerinin çoğalmasını engellemektedir (Yardim ve ark. 2020b). Antikanser ilaçlar sadece tümör hücrelerini değil, kemoterapi esnasinda dokuları ve büyüyen hücreleri de etkilemektedir. $\mathrm{Bu}$ nedenle, hepatotoksisite, nefrotoksisite, nörotoksisite, testis toksisitesi, kardiyak toksisite ve dalak toksisitesi gibi istenmeyen yan etkilere neden olmaktadır (Kandemir ve ark. 2011, Liu ve ark. 2015, Kandemir ve ark. 2017a, Benzer ve ark. 2018b, Celik ve ark. 2020d, Ozdemir ve ark. 2020). Antikanser ilaçlar, dalak dokusunda retiküloendotelyal sistem/mononükleer fagosit sistem tarafindan temizlenmektedir ve bu nedenle dalak dokusu sıklıkla toksikasyona maruz kalmaktadır (Liu ve ark. 2015).

Bazı kimyasal türlerinin uygulanmasıyla proteazom fonksiyonunun inhibisyonu sonucunda oksidatif stres indüklenmektedir (Perez-Galan ve ark. 2006, Maharjan ve ark. 2014). Bu kimyasallar arasinda kanser ilerlemesinin yavaşlatılmasında oldukça etkili sonuçları olan bortezomib (BTZ) de yer almakta ve anti-kanser ilaç olarak yaygın bir şekilde kullanılmaktadır (Hu ve ark. 2019, Ye ve ark. 2019). Yetişkin multipl miyelom için onaylanmış ilk proteazom inhibitörü olan bu ilacın (Richardson ve ark. 2005) apoptotik kaskattan önce reaktif oksijen türleri (ROS) üretimini arttırarak oksidatif strese yol açtığı bildirilmiştir (Perez-Galan ve ark. 2006).

Arginaz (E.C. 3.5.3.1), hepatositlerin sitoplamasinda bulunan arginaz-1 ve böbrek, ince bağırsak, dalak, meme bezleri, beyin, monositler ve makrofajların mitokondrilerinde eksprese edilen arginaz-2 olmak üzere iki izoformdan oluşan ve mangan içeren bir enzimdir (Kandemir ve Özdemir 2009). Toksik amonyağı ortadan kaldırmak için üre döngüsünün son reaksiyonu (L-argininin, L-ornitine ve üreye dönüştürülmesi) arginaz tarafindan katalize edilmektedir (Kandemir ve Özdemir 2008). Üre döngüsü sadece hepatositlerde bulunmasina rağmen, arginaz enzimi diğer birçok hücrede görülmektedir (Kandemir ve ark. 2013). Üre döngüsündeki işlevlerinin yanı sıra poliamin sentezi ve protein biyosentezi için gerekli prolinin üretimi gibi özel işlevlere de hizmet ettiği bildirilmiştir (Kandemir ve Özdemir 2008). Arginazın birçok metabolik işlevi olduğu, bazı hastalıklarda önemli rol oynadığı ve inflamatuar süreçlerde arginaz aktivitesinin arttığ1 bildirilmiștir (Kaya ve ark. 2020).

Son yillarda kanser tedavisinde kullanilan kemoterapötik ilaçların doz sınırlamasına yol açan toksik etkilerini hafifletmek amaciyla bitkisel kökenli ilaç denemeleri hız kazanmışırır (Taslimi ve ark. 2019). Bunlar arasinda fitokimyasallar, faydalı etkileri nedeniyle çeşitli hastalıkların tedavisinde araştırmacıların ilgi odağı haline gelmiştir (Aksu ve ark. 2017, Benzer ve ark. 2018a). Flavonoidler, antikanser ilaçların toksik etkisini önemli derecede azaltan antioksidan bileşiklerdir (Yardim ve ark. 2020a). Flavonlar, flavonoller, izoflavonlar, flavanonlar, flavanonoller ve kalkonlarla kategorize edilen flavonoidler, polifenolik bileşikler olarak bilinmektedir (Kucukler ve ark. 2020b). Berberis Vulgaris veya Coptis chinensis Franch.'deki aktif izokinolin alkaloidlerinden biri olan berberin, antiinflamatuvar, anti-diyabetik, anti-bakteriyel, hepatoprotektif ve nöroprotektif etkiler gibi birçok farmakolojik özelliğe sahiptir (Imenshahidi ve Hosseinzadeh 2016). Bunun yaninda berberin, nispeten yüksek dozlarda çok düşük toksisiteye sahip olduğu ve önemli klinik özellikleri ortaya çıkardığı için çok ilgi çekmiştir (Kumar ve ark. 2015).

Sunulan çalışmada, BTZ kaynaklı dalak hasarı üzerine berberinin etkilerinin biyokimyasal parametreler ile araştırılması amaçlanmıştır.

\section{MATERYAL ve METOT}

\section{Çalışmada Kullanılan İlaçlar}

Bortezomib (BTZ): Çalışmada kullanılan BTZ (Borcade 3.5mg IV/SC) Koçak Farma'dan (İstanbul, Türkiye) temin edildi.

Berberin: Antioksidan olarak kullanilan berberin Sigma-Aldrich (St. Louis, MO, ABD) firmasindan temin edildi.

\section{Deneyde Kullanılan Hayvanlar}

Çalışmada yaşları 8-10 haftalık olan 250-270 g ağırllğında toplam 35 adet Sprague Dawley cinsi erkek rat kullanildı. Ratlar, Atatürk Üniversitesi Tibbi Deneysel Uygulama ve Araştırma Merkezi'nden (Erzurum, Turkey) temin edildi. Uygulama öncesi 1 haftalık süre boyunca ratların ortama adaptasyonları sağlandı. Ortam şartları $24 \pm 1{ }^{\circ} \mathrm{C}$ ve $45 \pm 5 \%$ nem oranina sahipti. Ayrica ratların bulundukları ortamin 12 saat aydınlık/karanlık döngüsüne sahip olması sağlandi. Ratlar ad libitum olarak verilen standart pelet yem ve musluk suyu ile beslendiler. Bu çalışma, Atatürk Üniversitesi Hayvan Deneyleri Yerel Etik Kurulu tarafindan onaylanmıştır (Onay no: 20209/134).

\section{Deneysel Uygulamalar}

Ratlar, her grupta 7 hayvan olacak şekilde 5 farklı gruba ayrrldı. Doz seçiminde önceki literatürlerden yararlanild1 (Moghaddam ve ark. 2014, Xie ve ark. 2017). Deney tasarımı Tablo 1'de gösterildiği gibi bir kontrol ve dört deney grubu içermektedir; 
Tablo 1. Denemenin uygulama prosedürü

Table 1. Application procedure of the experiment

\begin{tabular}{|c|c|}
\hline Gruplar & Uygulama süreleri, dozları ve yöntemi \\
\hline Sağllklı Kontrol & Ratlara 1., 3., 5. ve 7. günlerde periton içi serum fizyolojik verildi \\
\hline Berberin & $\begin{array}{l}\text { Ratlara } 10 \text { gün boyunca her gün } 100 \mathrm{mg} / \mathrm{kg} \text { dozda berberin oral } \\
\text { olarak verildi. }\end{array}$ \\
\hline Bortezomib & $\begin{array}{l}\text { Ratlara 1., 3., 5. ve } 7 \text {. günlerde } 0.2 \mathrm{mg} / \mathrm{kg} \text { dozunda bortezomib } \\
\text { periton içi verildi. }\end{array}$ \\
\hline Bortezomib+Bereberin 50 & $\begin{array}{l}\text { Ratlara 1., 3., 5. ve 7. günlerde } 0.2 \mathrm{mg} / \mathrm{kg} \text { dozunda bortezomib } \\
\text { periton içi verldi. Bunun yanında } 10 \mathrm{gün} \text { boyunca her gün } 50 \mathrm{mg} / \mathrm{kg} \\
\text { dozda berberin oral olarak verildi. }\end{array}$ \\
\hline Bortezomib+Bereberin 100 & $\begin{array}{l}\text { Ratlara 1., 3., 5. ve 7. günlerde } 0.2 \mathrm{mg} / \mathrm{kg} \text { dozunda bortezomib } \\
\text { periton içi verildi. Bunun yanında } 10 \text { gün boyunca her gün } 100 \mathrm{mg} / \\
\text { kg dozda berberin oral olarak verildi. }\end{array}$ \\
\hline
\end{tabular}

Son berberin uygulamasından 24 saat sonra (11.gün) ratlar hafif sevofloran anestezisi altında dekapite edilerek dalak dokuları alındı. Dokular serum fizyolojik ile yikanarak biyokimyasal analizler yapilıncaya kadar $-20{ }^{\circ} \mathrm{C}$ 'de saklandi.

\section{Doku Homojenatlarının Hazırlanması}

Dalak dokusundan homojenat hazırlamak için, dokular MDA, GSH ve GPx analizleri için \%1,15 $\mathrm{KCl}$, SOD analizi için Tris- $\mathrm{HCl}$ tamponu ( $\mathrm{pH} 7,4)$ ve KAT ölçümü için Triton x-100 ile sulandırıldı. Elde edilen karışım, doku lizat cihazı (TissueLyser II, Qiagen) ile homojenize edildi. Homojenat MDA ölçümü için $+4{ }^{\circ} \mathrm{C}$ ve 3000 rpm'de 15 dakika, GSH ve GPx ölçümü için $+4{ }^{\circ} \mathrm{C}$ ve $11000 \mathrm{rpm}$ 'de 20 dakika, SOD ölçümü için $+4{ }^{\circ} \mathrm{C}$ ve $7000 \mathrm{rpm}$ 'de 60 dakika ve KAT ölçümü için $+4{ }^{\circ} \mathrm{C}$ ve $3500 \mathrm{rpm}$ 'de 10 dakika süreyle santrifüj edildi. Analizler için süpernatant kullanıldı.

Dalak Dokusunda Lipid Peroksidasyonu ve Antioksidan Enzim Aktivitelerinin Belirlenmesi Lipid peroksidasyon düzeyi, Placer ve ark. (1966) tarafindan geliştirilen yöntem ile MDA miktarı belirlenerek hesaplandı ve $\mathrm{nmol} / \mathrm{g}$ doku olarak sunuldu. Süperoksit dismutaz aktivitesi Sun ve ark. (1988) tarafindan tasarlanan yöntem ile ölçüldü. Sonuçlar U/g protein olarak verildi. Katalaz aktivitesinin ölçümü Aebi (1984) tarafından geliştirilen yöntem ile gerçekleştirildi ve sonuçlar katal/g protein olarak sunuldu. Glutatyon peroksidaz aktivitesi Lawrence ve Burk (1976) tarafindan geliştirilen yöntem ile ölçüldü. Sonuçlar $\mathrm{U} / \mathrm{g}$ protein olarak sunuldu. Sedlak ve Lindsay (1968) tarafindan sunulan yöntem ile GSH düzeyleri ölçüldü ve sonuçlar $\mathrm{nmol} / \mathrm{g}$ doku olarak verildi. Total protein analizi, sığır serum albuminini (BSA) standart olarak kullanarak Lowry ve ark. (1951) tarafindan belirlenen yöntem ile gerçekleştirildi.

Dalak Dokusunda Toplam Antioksidan ve Toplam Oksidan Kapasitelerinin Belirlenmesi Toplam antioksidan kapasite (TAK) ölçümü için Erel (2004) tarafindan ve toplam oksidan kapasite (TOK) ölçümü için yine Erel (2005) tarafindan geliştirilen ve kolorimetrik ölçüme dayanan ticari test kitleri (Rel Assay Diagnostics, Türkiye) kullanıldı.

Dalak Dokusunda Nitrik Oksit Düzeyi ve Arginaz Aktivitesinin Belirlenmesi

Dalak dokusunda toplam nitrik oksit (NO) seviyesini belirlemek için NO ölçüm kiti (Enzo Life Science) kullanıldı. Doku NO ölçümü, nitratın nitrite enzimatik dönüşümü ve Griess reaksiyonunun renkli bir azo boya ürünü olan nitritin kolorimetrik tespitine dayanmaktadır.

Arginaz aktivitesi, Geyer ve Dabich (1971) tarafindan açılanan tiyosemikarbazid-diasetilmonoksim üre yöntemi modifiye edilerek spektrofotometre ile belirlendi. Arginaz aktivitesi belirleme prensibi, Largininin arginaz tarafindan hidrolizi ile elde edilen ürenin spektrofotometrik ölçümüne dayanmaktadır. Bir ünite arginaz aktivitesi, $37^{\circ} \mathrm{C}$ 'de bir $\mu \mathrm{mol}$ üre/saat oluşumunu katalize eden enzim miktarı olarak ifade edilmektedir. Sonuçlar (spesifik aktivite) U/mg protein olarak sunuldu.

\section{İstatistiksel analiz}

Biyokimyasal yöntemlerle elde edilen verilerin istatistiksel olarak incelenmesi, tek yönlü varyans analizi (One-way ANOVA) ile yapıldı. Gruplar arasında farkın olup olmadığ1 Tukey's multiple comparison testi ile belirlendi. Sonuçlar ortalama \pm standart hata (S.E.M) olarak verildi. $\mathrm{P}<0.05$ değeri istatistiksel olarak anlaml kabul edildi.

\section{BULGULAR}

\section{Bortezomib ile İndüklenen Dalak Dokusunda} Berberinin Lipid Peroksidasyonu Üzerine Etkisi

Dalak dokusunda BTZ'nin neden olduğu lipid peroksidasyonuna karşı berberinin etkileri Şekil 1'de sunulmuştur. Elde edilen sonuçlar, BTZ'nin lipid peroksidasyonunun önemli bir göstergesi olan MDA seviyelerini kontrol grubuna göre arttırdığı belirlendi $(p<0.05)$. Bununla birlikte BTZ kaynaklı lipid peroksidasyonunun berberin ile hafifleyerek kontrol 
grubu seviyelerine yaklaştı̆̆ görüldü $(\mathrm{p}<0.05)$. Ek olarak berberinin farklı dozları arasinda istatistiksel olarak anlamlı bir fark olduğu tespit edildi $(\mathrm{p}<0.05)$.

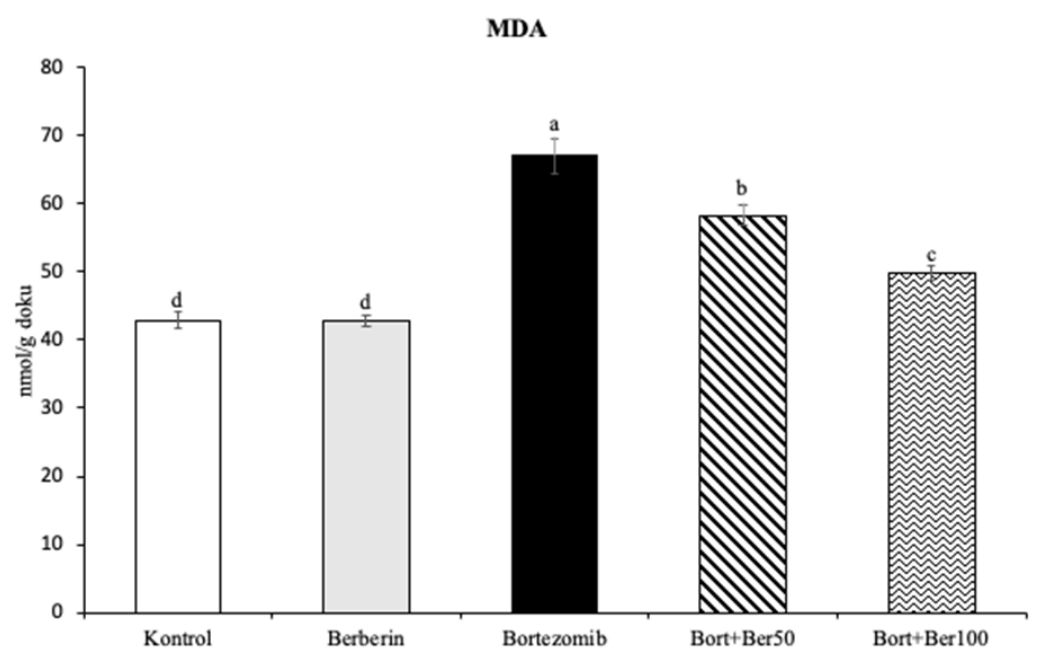

Şekil 1: Dalak dokusu MDA düzeyleri. Farklı harfler (a, b, c, d), gruplar arası farklılığı ifade etmektedir $(\mathrm{p}<0.05)$. Figure 1: Spleen tissue MDA levels. Different letters (a, b, c, d) express the difference between the groups $(\mathrm{p}<0.05)$

Bortezomib ile İndüklenen Dalak Dokusunda Berberinin Enzimatik ve Non-enzimatik Antioksidan Belirteçleri Üzerine Etkisi

Çalışmada, BTZ'nin antioksidan enzim aktivitelerini kontrol grubu ile karşılaştırıldığında inhibe ettiği belirlendi $(\mathrm{p}<0.05)$. Ayrıca vücuttaki önemli bir antioksidan olan GSH düzeylerinin BTZ uygulaması
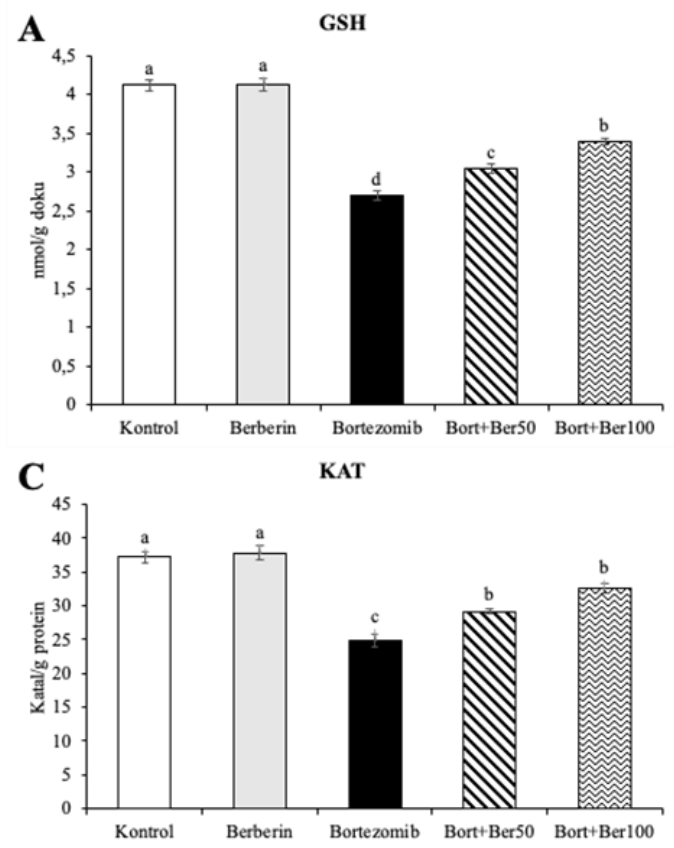

ile azaldığı görüldü $(\mathrm{p}<0.05)$. Bununla beraber BTZ ile birlikte berberin uygulamas1 yapilan gruplarda, BTZ grubuna göre GSH seviyelerinin arttığ1 ve SOD, KAT ve GPx aktivitelerinin kontrol grubu seviyelerine yaklaştığ1 belirlendi $(p<0.05)$. Dalak dokusunda enzimatik ve non-enzimatik belirteçlere ait tüm sonuçlar Şekil 2'de sunulmuştur.
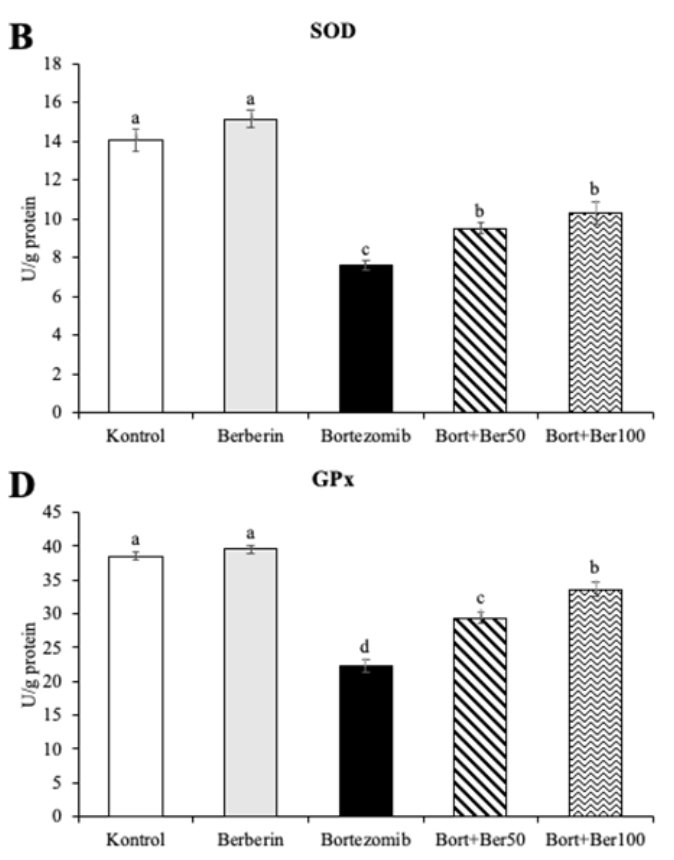

Şekil 2: Dalak dokusu GSH düzeyleri (A), SOD (B), KAT (C) ve GPx (D) aktiviteleri. Farklı harfler (a, b, c, d), gruplar arası farkll1ı̆ı ifade etmektedir $(\mathrm{p}<0.05)$.

Figure 2: Spleen tissue GSH levels (A), SOD (B) CAT (C) and GPx activities (D). Different letters (a, b, c, d) express the difference between the groups $(\mathrm{p}<0.05)$. 
Bortezomib ile İndüklenen Dalak Dokusunda Berberinin TAK-TOK ve OSI Üzerine Etkisi

Sunulan çalşsmada, BTZ'nin TOK'u ve OSI indeksini kontrol grubuna göre arttırdığ1, berberinin ise antioksidan özelliği sayesinde bu belirteçleri azalttığ tespit edildi $(\mathrm{p}<0.05)$. Ayrıca BTZ'nin dalak dokusunda antioksidan kapasiteyi düşürdügü görüldü $(p<0.05)$. Buna karşın BTZ'nin TAK'1 azalttığ1, berberin uygulamasının ise artırdığ belirlendi $(p<0.05)$. Berberinin farklı dozları arasında istatistiksel olarak önemli bir fark görüldü $(p<0.05)$. Dalak dokusunda TAK-TOK ile OSI'ye ait tüm sonuçlar Şekil 3’te sunulmuştur.
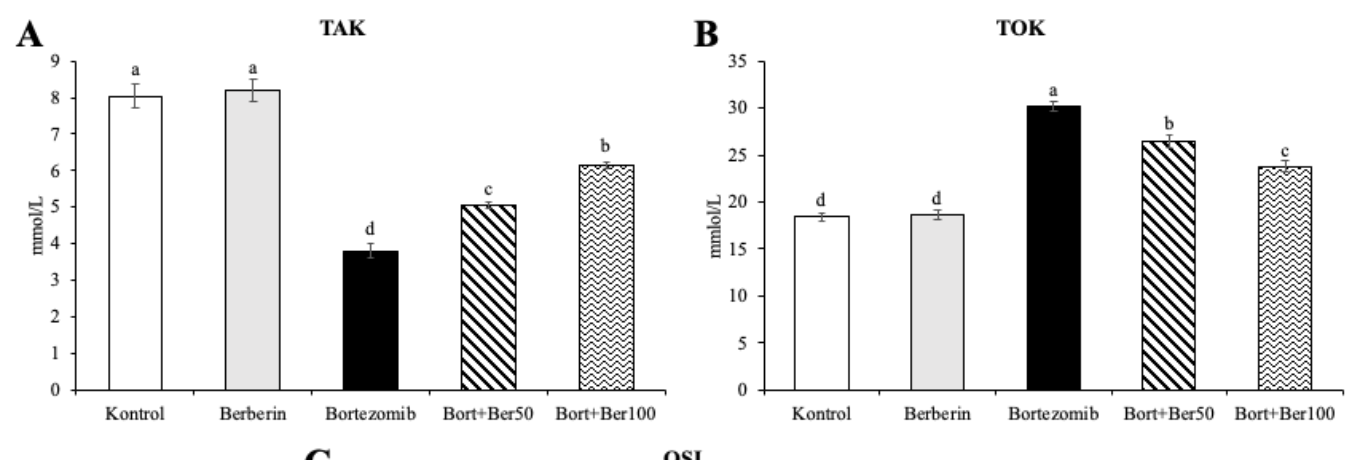

C

OSI

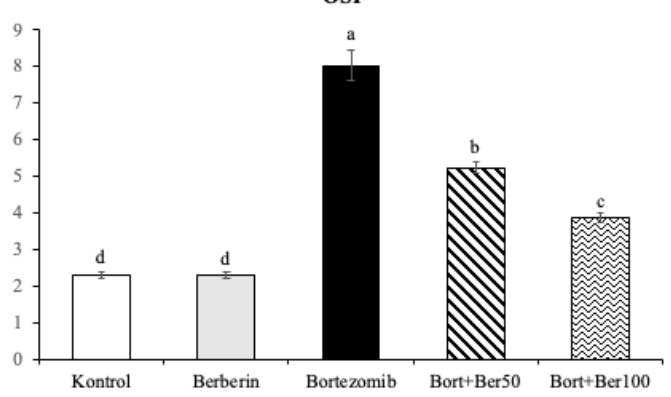

Şekil 3: Dalak dokusu TAK (A), TOK (B) ve OSI (C). Farklı harfler (a, b, c, d), gruplar arası farklılığ ifade etmektedir $(\mathrm{p}<0.05)$.

Figure 3: Spleen tissue TAS (A), TOS (B) and OSI (C). Different letters (a, b, c, d) express the difference between the groups $(\mathrm{p}<0.05)$.

Bortezomib ile İndüklenen Dalak Dokusunda Berberinin NO Seviyesi Üzerine Etkisi

Dalak dokusunda NO seviyeleri Șekil 4'te verilmiştir. Buna göre BTZ uygulaması yapılan ratların dalak dokularında NO seviyesinin kontrol grubuna göre oldukça yüksek olduğu belirlendi $(\mathrm{p}<0.05)$. BTZ ile birlikte berberin verilen gruplann NO seviyesini sadece BTZ uygulanan gruba göre doz bağımlı olarak azalttığ $\quad$ görüldü

$(\mathrm{p}<0.05)$.

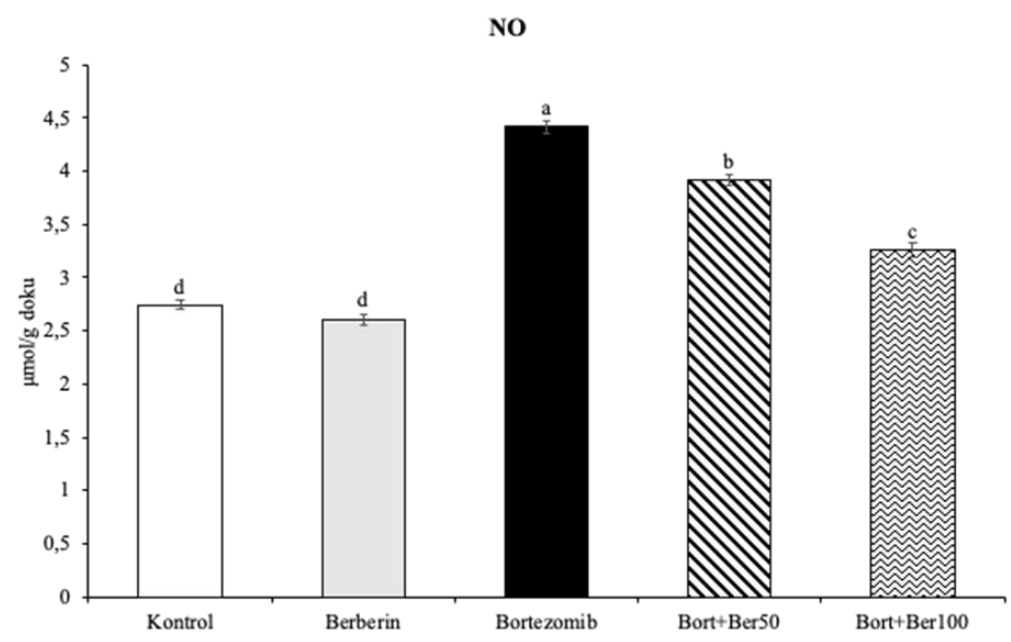

Şekil 4: Dalak dokusu NO seviyesi. Farklı harfler (a, b, c, d), gruplar arası farklılı̆ı ifade etmektedir $(\mathrm{p}<0.05)$.

Figure 4: Spleen tissue NO level. Different letters (a, b, c, d) express the difference between the groups $(p<0.05)$. 


\section{Bortezomib ile Indüklenen Dalak Dokusunda Berberinin Arginaz Aktivitesi Üzerine Etkisi}

Çalsşmada dalak dokusu arginaz aktivitesi ölçüldü ve elde edilen sonuçlar Şekil 5'te sunuldu. Elde edilen bulgulara göre kontrol grubu ile karşlaştırıldığında BTZ'nin dalak dokusu arginaz aktivitesinde düşüşe neden olduğu belirlendi $(\mathrm{p}<0.05)$. Berberin uygulaması ile BTZ kaynaklı arginaz aktivitesindeki düşüşün azaldığ1 ve kontrol seviyelerine yakın bir düzeye geldiği tespit edildi $(\mathrm{p}<0.05)$. Berberinin 50 ve $100 \mathrm{mg}$ dozlar1 arasinda da istatistiksel olarak anlamlı bir farkın olduğu görüldü $(\mathrm{p}<0.05)$.

\section{Arginaz}

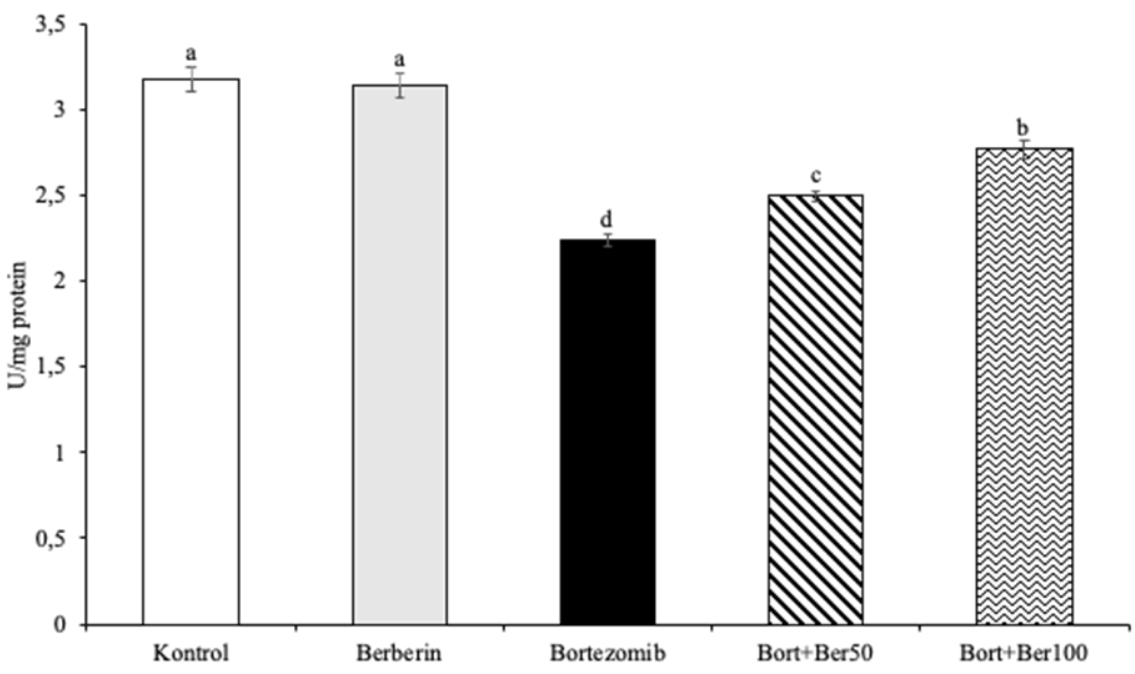

Şekil 5: Dalak dokusu arginaz aktivitesi. Farklı harfler (a, b, c, d), gruplar arası farklılı̆̆ ifade etmektedir ( $\mathrm{p}<0.05)$.

Figure 5: Spleen tissue arginase activity. Different letters (a, b, c, d) express the difference between the groups $(\mathrm{p}<0.05)$.

\section{TARTIŞMA}

Kanser, gelişmekte olan ülkelerde başlıca ölüm nedenlerinden biridir ve tedavisinde siklikla kemoterapötik maddeler kullanılmaktadır (Celik ve ark. 2020b). Anti-kanser ajanlar üzerinde yapilan çalışmalar tümörü etkileyen mekanizmaları netleştirse de bu ilaçların toksik etkileri üzerine doz sınırlamasına neden olan yan etkileri tam olarak bilinmemektedir. Ayrıca bu yan etkileri bertaraf etmek için gerekli çalışmalar da yetersiz kalmaktadır. Bu nedenle sunulan çalışmada, başta multipl miyelom olmak üzere prostat, meme, akciğer, böbrek ve yumurtalık kanserleri gibi çeşitli tümörlerin tedavisinde yaygın olarak kullanılan BTZ ile oluşturulan dalak toksisitesi üzerine berberinin etkileri araștırılmıștır.

Antioksidan enzimler ve bileşikler vücuttaki oksidan durumu dengelemede önemli rol oynamaktadırlar (Erişir ve ark. 2018). Hücrelerde antioksidan enzimlerin aktivitelerinde azalma ve antioksidan bileşiklerin tükenmesi sonucu oksidan maddelerin seviyelerinde artış meydana gelmekte ve bu durum oksidatif stres ile sonuçlanmaktadır (Yilmaz ve ark. 2020). Berberinin, ROS ve reaktif nitrojen türleri temizleyicisi olarak hareket ederek serbest radikallere ve dolayısıyla oksidatif strese karşı önemli bir koruyucu etkiye sahip olduğu bilinmektedir (Eftekhari ve ark. 2020). Daha önce yapılan bir çalışmada berberinin SOD, KAT ve GPx gibi antioksidan enzimlerin aktivitelerini ve GSH seviyesini artırdığ1 bildirilmiştir (Chen ve ark. 2016). Berberinin ayrıca
MDA ve NO seviyesi gibi oksidatif ve nitrosatif stres parametrelerini azalttığ 1 da rapor edilmiştir (Adil ve ark. 2016). BTZ gibi anti-kanser ilaçlar, serbest radikal oluşumunu artırip plazma yada doku antioksidan değerlerinde düşüşe yol açarak antioksidan savunma mekanizmasinin yetersiz kalmasina sebebiyet vermektedir (Celik ve ark. 2020c, Kandemir ve ark. 2020, Yardim ve ark. 2020c). Daha önce yapilan çalışmalarda, BTZ'nin serbest radikal oluşumunu artırarak lipid peroksidasyonuna neden olduğu ve böylece oksidatif stres meydana getirdiği rapor edilmiştir (Hou ve ark. 2014, Keles ve ark. 2014, Akaras ve ark. 2017). Dalak dokusundaki membran lipidleri, oksidasyona karşı oldukça duyarlıdır (Sutradhar ve ark. 2020). Gao ve ark. (2012) tarafından yapılan bir çalışmada proteaz inhibitörü uygulamasının dalak dokusunda hücre zarlarının peroksidasyonuna neden olduğu bildirilmiştir. Mevcut çalışmada dalak dokusunda BTZ (tek doz 0,2 mg / kg i.p.) uygulaması ile lipid peroksidasyonun önemli bir belirteci olan MDA düzeyinin arttığ1, berberin uygulamasında ise azaldığı tespit edildi. Sonuçlar değerlendirildiğinde, BTZ'nin lipid peroksidasyonuna neden olarak MDA seviyesinde yükselmeye sebep olduğu, berberinin ise bu hasarı azaltarak membran lipidlerinin korunmasında önemli bir rol oynadığ 1 belirlendi.

Oksidatif strese karşı savunmada önemli bir rol oynayan enzimatik (SOD, CAT ve GPx) ve nonenzimatik (GSH) antioksidanlar, ROS'un etkilerini azaltarak veya tamamen ortadan kaldırarak hücrelere 
verilen hasarı engellemektedir/önlemektedir (Buyuklu ve ark. 2015, Kandemir ve ark. 2017b). Kemoterapötiklerin serbest radikallerin üretimine neden olarak SOD, KAT ve GPx aktivitelerini ve GSH seviyelerini düşürdüğü birçok çalışma ile gösterilmiştir (Taslimi ve ark. 2019, Celik ve ark. 2020a, Kucukler ve ark. 2020a, Temel ve ark. 2020). Akaras ve ark. (2020) tarafindan yapılan çalışmada BTZ'nin serbest radikal üretiminde artışa sebep olduğu ve bunun sonucunda SOD, KAT ve GPx aktivitelerini ve GSH seviyelerini düşürdüğü için ciddi hasar oluşturduğu bildirilmiştir. Mevcut çalışmada, BTZ uygulanan grupta azalan GSH düzeylerinin berberin gruplarında yükseldiği tespit edildi. BTZ uygulanan grupta SOD, KAT ve GPx enzim aktivitelerinin düştüğü, buna karşı berberin uygulanan gruplarda bu enzimlerin aktivitelerinin arttığı bulundu. $\mathrm{Bu}$ sonuçlar, berberinin dalak dokusunda BTZ tarafindan meydana gelen oksidatif stresi azaltabildiğini/önleyebildiğini ve antioksidan enzim aktivitelerini ve GSH seviyelerini artırarak hücreleri olası hasarlardan koruyabildiğini göstermektedir.

Canlı organizmadaki antioksidan kapasite hakkında önemli bilgi veren TAK ve oksidan kapasitesini gösteren TOK son yıllarda sıklıkla kullanılan önemli biyokimyasal parametrelerdir. Dalak dokusunda BTZ'nin etkileri tam olarak açıklanmamıs ve bu konu ile ilgili yapılan çalışmalarda TAK ve TOK incelenmemiştir. Daha önce yapılan çeşitli çalışmalarda enfeksiyoz ve paraziter etkenler ile iskemi-reperfüzyonun TAK seviyesini düşürüp TOK seviyesini artırdığı ve böylece organizmay1 strese sürüklediği bildirilmiştir (Yildiz ve ark. 2010, Hanedan ve ark. 2015, Aktas ve ark. 2017). Kemoterapötik uygulanan ratlarda da toplam antioksidan kapasitenin düştüğü toplam oksidan kapasitesinin ise arttı̆̆1 tespit edilmiştir (Al-malky ve ark. 2019, Abdelhazer ve ark. 2020, Arafa ve Atteia 2020). Sunulan çalışmada, hem $50 \mathrm{mg} / \mathrm{kg}$ hem de $100 \mathrm{mg} / \mathrm{kg}$ berberin uygulanmasinın TAK'1 yükseltirken TOK'u düşürdüğü tespit edildi. Yapılan analizler sonucunda, berberinin BTZ kaynaklı dalak toksisitesine karş1 antioksidan kapasiteyi artırarak koruyucu etki gösterdiği kanısina varıldı. OSI, oksidatif stresin anahtar belirteçlerinden biridir (Orciuolo ve ark. 2007). Çalışmada BTZ uygulanan grupta OSI'nin arttığ1, BTZ ile berberin uygulanan gruplarda ise doza bağlı olarak azaldığı tespit edildi.

Reaktif nitrojen türleri gibi radikallerin üretimi, dalak toksisitesinin önemli bir belirteci olarak öne sürülmektedir (Kaya ve ark. 2020). Nitrosatif stres, nitrik oksitin (NO) oksidatif metabolizmasina yol açmaktadır (Li ve ark. 2012). NO, endojen bir vazodilatördür (Araujo ve Welch 2006) ve çeşitli hücresel fizyolojik ve patofizyolojik durumlara aracilik eder. Aşır1 miktarda NO üretimi, peroksinitrit ve nitrojen dioksit gibi reaktif nitrojen türlerinin oluşumuna neden olmaktadır (Kaya ve ark. 2020). Yapılan çalışmalarda dalak toksikasyonu durumunda NO seviyelerinin arttığ1 tespit edilmiştir (Al-Quraishy ve ark. 2020, Wang ve ark. 2020). Sunulan çalışmada, dalak dokusundaki NO seviyelerinde BTZ grubunda artış, berberin uygulanan gruplarda ise doza bağlı bir azalış tespit edildi. Arginaz, üre ve ornitin üretmek amacıyla aynı substrat için (L-arginin) nitrik oksit sentaz (NOS) ile rekabet etmektedir. Ornitin, doku onarımı,yara iyileşmesi ve hücresel büyüme için gerekli olan poliamin üretim yollarına dahil olmaktadır. Poliaminler NOS'u baskılamaktadır (Rath ve ark. 2014). Akomolafe ve ark. (2020) tarafindan gerçekleştirilen bir çalışmada kemoterapötik uygulanan ratlarda toksik grubun arginaz aktivitesi kontrol grubundan anlamlı derecede yüksek bulunmuştur. Gerçekleştirilen başka bir çalışmada araştırıcılar oksidatif stres durumunda arginaz aktivitesinin azaldığını rapor etmişlerdir (Ali ve Zeyadi 2020). Sunulan çalışmada yalnız BTZ uygulanan ratlarda arginaz aktivitesi azalırken, BTZ ile berberinin beraber uygulandığı gruplarda artış tespit edildi. Dalak dokusunda berberin dozuna bağlı olarak artan arginaz aktivitesi L-arginin'in üre ve ornitine dönüşmesini sağlayarak NOS için L-arginin kullanılabilirliğini azaltmakta, bu da NOS'un azalan aktivitesinden dolayı NO üretiminde düşüşe neden olmaktadır. Nitrik oksit üretimindeki bu azalmadan dolayı nitrrosatif stres etkinliği düşmektedir.

Sonuç olarak BTZ'nin dalak dokusunda oksidanantioksidan dengeyi bozduğu, NO seviyesini artırıp, arginaz aktivitesini azalttığ ve buna bağlı olarak oksidatif hasara neden olduğu belirlenmiş, berberinin ise BTZ kaynaklı bu hasarı azalttığı tespit edilmiştir. Konu ile ilgili yapılacak ileri düzey çalışmalar ile BTZ kaynaklı dalak hasarını azaltmada/engellemede berberinin alternatif tedavi yöntemi olarak yerini alacağ1 ve konuyla ilgili farklı çalışmalara katkı sağlayacağı düşünülmektedir.

Etik Kurul Bilgileri : $\mathrm{Bu}$ çalıșma, Atatürk Üniversitesi Hayvan Deneyleri Yerel Etik Kurulu tarafindan onaylanmıştır (Onay no: 2020-9/134).

Çıkar Çatışması: Yazarlar, çıkar çatışması olmadığını beyan eder.

\section{KAYNAKLAR}

Abdelhazer WY, Khalaf HM, El-Hussieny M, Bayoumi AMA, Shehata S, Refaie MMM. Role of nitric oxide donor in methotrexate-induced testicular injury via modulation of proinflammatory mediators, eNOS and Pglycoprotein. Hum Exp Toxicol. 2020; 39(12): 1700-1709.

Adil M, Kandhare AD, Dalvi G, Ghosh P, Venkata S, Raygude KS, Bodhankar SL. Ameliorative effect of berberine against gentamicin-induced nephrotoxicity in rats via attenuation of oxidative stress, inflammation, apoptosis and mitochondrial dysfunction. Ren Fail. 2016; 38(6): 996-1006.

Aebi H. Catalase in vitro. Methods Enzymol. 1984; 105 121-126. 
Akaras N, Abuc OO, Koc K, Bal T, Geyikoglu F, Atilay H, Erol HS, Yigit S, Gul M. (1 --> 3)-beta-d-glucan enhances the toxicity induced by Bortezomib in rat testis. J Food Biochem. 2020; 44(3): e13155.

Akaras N, Bal T, Atilay H, Selli J, Halici MB. Protective effects of agomelatine on testicular damage caused by bortezomib. Biotech Histochem. 2017; 92(8): 552-559.

Akomolafe SF, Olasehinde TA, Oyeleye SI, Aluko TB, Adewale OO, Ijomone OM. Curcumin Administration Mitigates Cyclophosphamide-Induced Oxidative Damage and Restores Alteration of Enzymes Associated with Cognitive Function in Rats' Brain. Neurotox Res. 2020; 38: 199-210.

Aktas MS, Kandemir FM, Kirbas A, Hanedan B, Aydin MA. Evaluation of oxidative stress in sheep infected with Psoroptes ovis using total antioxidant capacity, total oxidant status, and malondialdehyde level. J Vet Res. 2017; 61(2): 197-201.

Aksu EH, Kandemir FM, Özkaraca M, Ömür AD, Küçükler S, Çomaklı S. Rutin ameliorates cisplatin-induced reproductive damagevia suppression of oxidative stress and apoptosis in adultmale rats. Andrologia. 2017; 49(1): e12593.

Ali EMM, Zeyadi MA. Impact of caffeic acid phenylester on nitric oxide synthase and arginase in rats intoxicated with nitrites. J King Saud Univ Sci. 2020; 32(4): 2454-2461.

Al-malky H, Osman AM, Damanhouri ZA, Alkreathy HM, Al Aama JY, Ramadan WS, Al Qahtani AA, Al Mahdi HB. Modulation of doxorubicin-induced expression of the multidrug resistance gene in breast cancer cells by diltiazem and protection against cardiotoxicity in experimental animals. Cancer Cell Int. 2019; 19: 191. DOI: 10.1186/s12935-019-0912-0

Al-Quraishy S, Murshed M, Delic D, Al-Shaebi EM, Qasem MAA, Mares MM, Dkhil MA. Plasmodium chabaudiinfected mice spleen response tosynthesized silver nanoparticles from Indigofera oblongifolia extract. Lett Appl Microbiol. 2020; 71(5): 542-549.

Arafa MH, Atteia HH. Protective Role of Epigallocatechin Gallate in a Rat Model of Cisplatin-Induced Cerebral Inflammation and Oxidative Damage: Impact of Modulating NF- $x \mathrm{~B}$ and Nrf2. Neurotox Res. 2020; 37: 380-396.

Araujo M, Welch WJ. Oxidative stress and nitric oxide in kidney function. Curr Opin Nephrol Hy. 2006; 15(1): 72-77.

Benzer F, Kandemir FM, Kucukler S, Comakli S, Caglayan C. Chemoprotective effects of curcumin on doxorubicininduced nephrotoxicity in wistar rats: by modulating inflammatory cytokines, apoptosis, oxidative stress and oxidative DNA damage. Arch Physiol Biochem. 2018a; 124 (5): 448-457.

Benzer F, Kandemir FM, Ozkaraca M, Kucukler S, Caglayan C. Curcumin ameliorates doxorubicin-induced cardiotoxicity by abrogation of inflammation, apoptosis, oxidative DNA damage, and protein oxidation in rats. J Biochem Mol Toxic. 2018b; 32(2): e22030.

Buyuklu M, Kandemir FM, Ozkaraca M, Set T, Bakirci EM, Topal E, Ileriturk M, Turkmen K. Benefical effects of lycopene against contrast medium-induced oxidative stress, inflammation, autophagy, and apoptosis in rat kidney. Hum Exp Toxicol. 2015; 34(5): 487-496.

Celik H, Kandemir FM, Caglayan C, Ozdemir S, Comakli S, Kucukler S, Yardim A. Neuroprotective efect of rutin against colistin-induced oxidative stress, infammation and apoptosis in rat brain associated with the CREB/BDNF expressions. Mol Biol Rep. 2020a; DOI: 10.1007/s11033020-05302-z

Celik H, Kucukler S, Comakli S, Caglayan C, Ozdemir S, Yardim A, Karaman M, Kandemir FM. Neuroprotective effect of chrysin on isoniazid-induced neurotoxicity via suppression of oxidative stress, inflammation and apoptosis in rats. Neurotoxicology. 2020b; 81: 197-208.

Celik H, Kucukler S, Comakli S, Ozdemir S, Caglayan C, Yardim A, Kandemir FM. Morin attenuates ifosfamideinduced neurotoxicity in rats via suppression of oxidative stress, neuroinflammation and neuronal apoptosis. Neurotoxicology. 2020c; 76: 126-137.

Celik H, Kucukler S, Ozdemir S, Comakli S, Gur C, Kandemir FM, Yardim A. Lycopene protects against central and peripheral neuropathy by inhibiting oxaliplatin-induced ATF-6 pathway, apoptosis, inflammation and oxidative stress in brains and sciatic tissues of rats. Neurotoxicology. 2020d; 80: 29-40.

Chen X, Zhang Y, Zhu Z, Liu H, Guo H, Xiong C, Xie K, Zhang $\mathbf{X}$, Su S. Protective effect of berberine on doxorubicininduced acute hepatorenal toxicity in rats. Mol Med Rep. 2016; 13(5): 3953-3960.

Eftekhari A, Hasanzadeh A, Khalilov R, Hosainzadegan H, Ahmadian E, Eghbal MA. Hepatoprotective role of berberine against paraquat-induced liver toxicity in rat. Environ Sci Pollut Res. 2020; DOI: 10.1007/s1135607232-1.

Erel O. A novel automated direct measurement method for total antioxidant capacity using a new generation, more stable ABTS radical cation. Clin Biochem. 2004; 37(4): 277-285.

Erel O. A new automated colorimetric method for measuring total oxidant status. Clin Biochem. 2005; 38(12): 11031111.

Erişir M, Benzer F, Özkaya A, Dağ Ü. Kurşun Uygulanan Ratların Bazı Dokularında (Kalp, Akciğer, Beyin, Dalak, Kas) Oksidatif Stress Üzerine Naringeninin Etkisi. Atatürk Üniversitesi Vet Bil Derg. 2018; 13(1): 34-41.

Gao C, Liu Y, Ma L, Wang S. Protective effects of ulinastatin on pulmonary damage in rats following scald injury. Burns. 2012; 38(7): 1027-1034.

Geyer JW, Dabich D. Rapid Method for Determination of Arginase Activity in Tissue Homogenates. Anal Biochem. 1971; 39(2): 412-417.

Hanedan B, Kirbas A, Kandemir FM, Ozkaraca M, Kilic K, Benzer F. Arginase activity and total oxidant/antioxidant capacity in cows with lung cystic echinococcosis. Med Weter. 2015; 71(3): 167-170.

Hou M, Erikkson E, Svechnikov K, Jahnukainen K, Söder O, Meinhardt A, Sävendahl L. Bortezomib treatment 
causes long-term testicular dysfunction in young male mice. Mol Cancer. 2014; 13(1): 155-165.

Hu B, Zhou Q, Hu YY, Zhuang L, Yi LP, Cao JX, Li TQ, Wang J. Efficacy and Safety of Once-Weekly versus Twice-Weekly Bortezomib in Patients with Hematologic Malignancies: A Meta-analysis with Trial Sequential Analysis. Pharmacotherapy. 2019; 39(6): 697-708.

Imenshahidi $\mathbf{M}$, Hosseinzadeh $\mathbf{H}$. Berberis Vulgaris and Berberine: An Update Review. Phytother Res. 2016; 30(11): 1745-1764.

Kandemir FM, Benzer F, Yildirim NC, Ozdemir N. Compensatory effects of curcumin on cisplatin-induced toxicity in rabbit testis. J Med Plants Res. 2011; 5(3): 456461.

Kandemir FM, Hanedan B, Aktaş MS, Küçükler S, Çağlayan C. Ratlarda Sisplatinden Kaynaklanan Nefrotoksisite Üzerine Rutinin İyileştirici Etkileri. Fırat Univ Vet J Health Sci. 2020; 34(3): 147-151.

Kandemir FM, Kucukler S, Caglayan C, Gur C, Batil AA, Gulcin I. Therapeutic effects of silymarin and naringin on methotrexate-induced nephrotoxicity in rats: Biochemical evaluation of anti-inflammatory, antiapoptotic, and antiautophagic properties. J Food Biochem. 2017a; 41(5): e12398.

Kandemir FM, Küçükler S, Çağlayan C. Beneficial effects of silymarin and naringin against methotrexate-induced hepatotoxicity in rats. Atatürk Üniversitesi Vet Bil Derg. 2017b; 12: 167-177.

Kandemir, FM, Özdemir, N. L- Lizin ve L- Ornitinin Sı̆̆ır Böbrek Doku Arginaz Aktivitesi Üzerine İnhibisyon Etkisi. Fırat Üniversitesi Sağ Bil Derg. 2008; 22(1): 1-4.

Kandemir FM, Özdemir N. Some Kinetic Properties of Arginase in Sheep Spleen Tissue. Kafkas Univ Vet Fak Derg. 2009; 15(4): 553-559.

Kandemir FM, Yüksel M, Özdemir N, Deveci H. A different approach to diagnosis of subclinical mastitis: milk arginase activity. Vet Arhiv. 2013; 83(6): 603-610.

Kaya SO, Gur S, Erisir M, Kandemir FM, Benzer F, Kaya E, Turk G, Sonmez M. Influence of vitamin $\mathrm{E}$ and vitamin E-selenium combination on arginase activity, nitric oxide level and some spermatological properties in ram semen. Reprod Domest Anim. 2020; 55: 162-169.

Keles ON, Can S, Cigsar G, Colak S, Erol HS, Akaras N, Erdemci B, Bilgin BC, Can I, Unal B, Halici MB. Hepatoprotective Effects of B-1,3-(D)-Glucan on Bortezomib-Induced Liver Damage in Rats. Kafkas Univ Vet Fak Derg. 2014; 20(6): 929-938.

Kucukler S, Darendelioglu E, Caglayan C, Ayna A, Yildirim S, Kandemir FM. Zingerone attenuates vancomycininduced hepatotoxicity in rats through regulation of oxidative stress, inflammation and apoptosis. Life Sci. 2020a; 259: 118382.

Kucukler S, Ozdemir S, Comakli S, Kandemir FM. Effects of Chrysin Against Isoniazid-Induced Lung Injury in Rats. Kocatepe Vet J. 2020b; 13(2): 161-171.
Kumar A, Ekavali Chopra K, Mukherjee M, Pottabathini R, Dhull DK. Current knowledge and pharmacological profile of berberine: An update. Eur J Pharmacol. 2015; 761: 288-297.

Lawrence RA, Burk RF. Glutathione Peroxidase-Activity in Selenium-Deficient Rat-Liver. Biochem Bioph Res Co. 1976; 71(4): 952-958.

Li XL, Li HL, Lu NH, Feng YC, Huang Y, Gao ZH. Iron increases liver injury through oxidative/nitrative stress in diabetic rats: Involvement of nitrotyrosination of glucokinase. Biochimie. 2012; 94(12): 2620-2627.

Liu L, Ye Q, Lu MG, Lo YC, Hsu YH, Wei MC, Chen YH, Lo SC, Wang SJ, Bain DJ, Ho C. A New Approach to Reduce Toxicities and to Improve Bioavailabilities of Platinum-Containing Anti-Cancer Nanodrugs. Sci RepUk. 2015; 5: 10881.

Lowry OH, Rosebrough NJ, Farr AL. Randall, RJ, Protein measurement with the Folin phenol reagent. J Biol Chem. 1951; 193(1): 265-275.

Maharjan S, Oku M, Tsuda M, Hoseki J, Sakai Y. Mitochondrial impairment triggers cytosolic oxidative stress and cell death following proteasome inhibition. Sci Rep-Uk. 2014; 4: 5896. DOI: 10.1038/srep05896

Moghaddam HK, Baluchnejadmojarad T, Roghani M, Khaksari M, Norouzi P, Ahooie M, Mahboobi F. Berberine Ameliorate Oxidative Stress and Astrogliosis in the Hippocampus of STZ-Induced Diabetic Rats. Mol Neurobiol. 2014; 49(2): 820-826.

Orciuolo E, Buda G, Cecconi N, Galimberti S, Versari D, Cervetti G, Salvetti A, Petrini M. Unexpected cardiotoxicity in haematological bortezomib treated patients. Brit J Haematol. 2007; 138(3): 396-397.

Ozdemir S, Kucukler S, Comakli S, Kandemir FM. The protective effect of Morin against ifosfamide-induced acute liver injury in rats associated with the inhibition of DNA damage and apoptosis. Drug Chem Toxicol. 2020; DOI: $10.1080 / 01480545.2020 .1822390$

Perez-Galan P, Roue G, Villamor N, Montserrat E, Campo E, Colomer D. The proteasome inhibitor bortezomib induces apoptosis in mantle-cell lymphoma through generation of ROS and Noxa activation independent of p53 status. Blood. 2006; 107(1): 257-264.

Placer ZA, Cushman LL, Johnson BC. Estimation of product of lipid peroxidation (malonyl dialdehyde) in biochemical systems. Anal Biochem. 1966; 16(2): 359-364.

Rath M, Müller I, Kropf P, Closs EI, Munder M. Metabolism via Arginase or Nitric Oxide Synthase: Two Competing Arginine Pathways in Macrophages. Front Immunol. 2014; 5: 532. DOI: 10.3389/fimmu.2014.00532.

Richardson PG, Sonneveld P, Schuster MW, Irwin D, Stadtmauer EA, Facon T, Harousseau JL, BenYehuda D, Lonial S, Goldschmidt H, Reece D, SanMiguel JF, Blade J, Boccadoro M, Cavenagh J, Dalton WS, Boral AL, Esseltine DL, Porter JB, Schenkein D, Anderson KC. Assessment of Proteasome Inhibition for Extending Remissions, I, Bortezomib or high-dose dexamethasone for relapsed multiple myeloma. N Engl J Med. 2005; 352(24): $2487-$ 2498. 
Sedlak J, Lindsay RH. Estimation of total, protein-bound, and nonprotein sulfhydryl groups in tissue with Ellman's reagent. Anal Biochem. 1968; 25(1): 192-205.

Sun Y, Oberley LW, Li Y. A simple method for clinical assay of superoxide dismutase. Clin Chem. 1988; 34(3): 497-500.

Sutradhar S, Deb A, Singh SS. Melatonin attenuates diabetesinduced oxidative stress in spleen and suppression of splenocyte proliferation in laboratory mice. Arch Physiol Biochem. 2020; 1-12.

Taslimi P, Kandemir FM, Demir Y, Ileriturk M, Temel Y, Caglayan C, Gulcin I. The antidiabetic and anticholinergic effects of chrysin on cyclophosphamideinduced multiple organ toxicity in rats: Pharmacological evaluation of some metabolic enzyme activities. J Biochem Mol Toxicol 2019; 33(6): e22313.

Temel, Y, Caglayan C, Ahmed BM, Kandemir FM, Ciftci M. The effects of chrysin and naringin on cyclophosphamide-induced erythrocyte damage in rats: biochemical evaluation of some enzyme activities in vivo and in vitro. Naunyn-Schmiedeberg's Arch Pharmacol. 2020; DOI: 10.1007/s00210-020-01987-y

Wang M, Xiong Y, Zhu W, Ruze1 R Xu Q,Yan Z,Zhu J,Zhong M,Cheng Y,Hu S,Zhang G. Sleeve Gastrectomy Ameliorates Diabetes-Related Spleen Damage by Improving Oxidative Stress Status in Diabetic Obese Rats. Obes Surg. 2020; DOI: 10.1007/s11695-02005073-3

Xie JD, Chen SR, Chen H, Pan HL. Bortezomib induces neuropathic pain through protein kinase C-mediated activation of presynaptic NMDA receptors in the spinal cord. Neuropharmacology. 2017; 123: 477-487.

Yardim A, Kandemir FM, Comakli S, Ozdemir S, Caglayan C, Kucukler S, Celik H. Protective Effects of Curcumin Against Paclitaxel-Induced Spinal Cord and Sciatic Nerve Injuries in Rats. Neurochem Res. 2020a; DOI: $10.1007 /$ s11064-020-03174-0

Yardim A, Kandemir FM, Ozdemir S, Kucukler S, Comakli S, Gur C, Celik H. Quercetin provides protection against the peripheral nerve damage caused by vincristine in rats by suppressing caspase $3, \mathrm{NF}-x \mathrm{~B}, \mathrm{ATF}-6$ pathways and activating Nrf2, Akt pathways. Neurotoxicology. 2020b; 81: 137-146.

Yardim A, Kucukler S, Ozdemir S, Comakli S, Caglayan C, Kandemir FM, Celik H. Silymarin alleviates docetaxelinduced central and peripheral neurotoxicity by reducing oxidative stress, inflammation and apoptosis in rats. Gene. 2020c; DOI: 10.1016/j.gene.2020.145239.

Ye ZQ, Chen J, Xuan ZX, Yang WC, Chen J. Subcutaneous bortezomib might be standard of care for patients with multiple myeloma: a systematic review and meta-analysis. Drug Des Dev Ther. 2019; 13: 1707-1716.

Yildiz F, Terzi A, Coban S, Bitiren M, Celik H, Aksoy N, Ozdogan MK, Cakir H. Purified micronized flavonoid fraction ameliorates the injury of spleen and ileum secondary to hepatic ischemia-reperfusion in rats. Dig Dis Sci. 2010; 55(8): 2237-2243.

Yilmaz S, Kandemir FM, Kaya E, Ozkaraca M. Chemoprotective Effects of Propolis on Aflatoxin B1Induced Hepatotoxicity in Rats: Oxidative Damage and
Hepatotoxicity by Modulating TP53, Oxidative Stress. Curr Proteomics. 2020; 17(3): 191-199. 